\title{
Metabolic and endocrine response to exercise: sympathoadrenal integration with skeletal muscle
}

\author{
Derek Ball \\ School of Life Sciences, Heriot-Watt University, Edinburgh EH14 4AS, UK
}

Correspondence should be addressed to $D$ Ball

Email

D.Ball@hw.ac.uk

\begin{abstract}
Skeletal muscle has the capacity to increase energy turnover by $\sim 1000$ times its resting rate when contracting at the maximum force/power output. Since ATP is not stored in any appreciable quantity, the muscle requires a coordinated metabolic response to maintain an adequate supply of ATP to sustain contractile activity. The integration of intracellular metabolic pathways is dependent upon the cross-bridge cycling rate of myosin and actin, substrate availability and the accumulation of metabolic byproducts, all of which can influence the maintenance of contractile activity or result in the onset of fatigue. In addition, the mobilisation of extracellular substrates is dependent upon the integration of both the autonomic nervous system and endocrine systems to coordinate an increase in both carbohydrate and fat availability. The current review examines the evidence for skeletal muscle to generate power over short and long durations and discusses the metabolic response to sustain these processes. The review also considers the endocrine response from the perspective of the sympathoadrenal system to integrate extracellular substrate availability with the increased energy demands made by contracting skeletal muscle. Finally, the review briefly discusses the evidence that muscle acts in an endocrine manner during exercise and what role this might play in mobilising extracellular substrates to augment the effects of the sympathoadrenal system.
\end{abstract}

\section{Key Words}

- muscle energetics

- endocrine

- sympathoadrenal

cytokine

\section{Introduction}

Over 60 years ago, Morris et al. (1953) published data examining the relationship between the occupation of London bus drivers and conductors with the incidence of cardiovascular disease (CVD) and sudden cardiac death. Their report revealed that the incidence rate of the first clinical manifestations of CVD in the active conductors was half of that observed in the sedentary drivers. They subsequently published findings showing a cardioprotective effect of physical activity in relationship with the incidence of sudden cardiac death (Heady et al. 1961). The conclusion from these studies was that the greater physical demands placed on the conductors resulted in a lower incidence of CVD when compared with the more sedentary drivers. Although exercise is now widely recognised as an effective counter measure to the development of diseases such as CVD, diabetes, cancer and obesity, our understanding of the interrelationships between the mechanisms of systemic and peripheral responses to exercise and the underlying reasons for disease prevention are largely incomplete.

Our understanding of the metabolic, hormonal and genetic responses to exercise has increased substantially

Published by Bioscientifica Ltd 
since the work of Morris et al. (1953). Repeated exercise has been shown to improve insulin sensitivity (Borghouts \& Keizer 2000, Kirwan et al. 2009, Malin et al. 2013, Goyaram et al. 2014), reduce the catecholamine response to exercise (Kjaer \& Galbo 1988), increase lipid catabolism (Phillips et al. 1996, Henderson \& Alderman 2014), improve arterial compliance and endothelial function (Seals et al. 2008, Pierce et al. 2011) and maintain both bone density and skeletal muscle mass during ageing (Layne \& Nelson 1999) and maintain muscle metabolic capacity with ageing (Olesen et al. 2014). Recent work has suggested that both skeletal muscle and adipose tissue function as integrated endocrine organs in response to an exercise stimulus (Pedersen 2013). Exercise therefore continues to be an effective methodological tool to study the body's response to metabolic stress, and from a clinical perspective, offers an alternative treatment choice to drug intervention strategies. Exercise also provides a quantifiable and controllable mechanism to examine the effects of increasing the demands for ATP production and the integration of several organ systems to meet these demands (see Fig. 1). Finally, exercise facilitates our understanding of the emerging role of muscle and adipose tissue as endocrine organs.

The rising incidence of diseases related to physical inactivity and the links to endocrine dysfunction continue to challenge worldwide health care programmes in addressing the deleterious effects of low physical activity on population health (Global Strategy on Diet, Physical Activity and Health' WHO 2004). The current review describes the metabolic capacity of skeletal muscle in the transition from rest to maximum energy turnover. The review also discusses the process of responding to this metabolic stress through the co-ordinated utilisation of intra and extra-muscular energy stores that skeletal muscle employs. Finally, the review discusses the established view of the endocrine response to exercise from the perspective of sympathoadrenal activity and introduces the concept

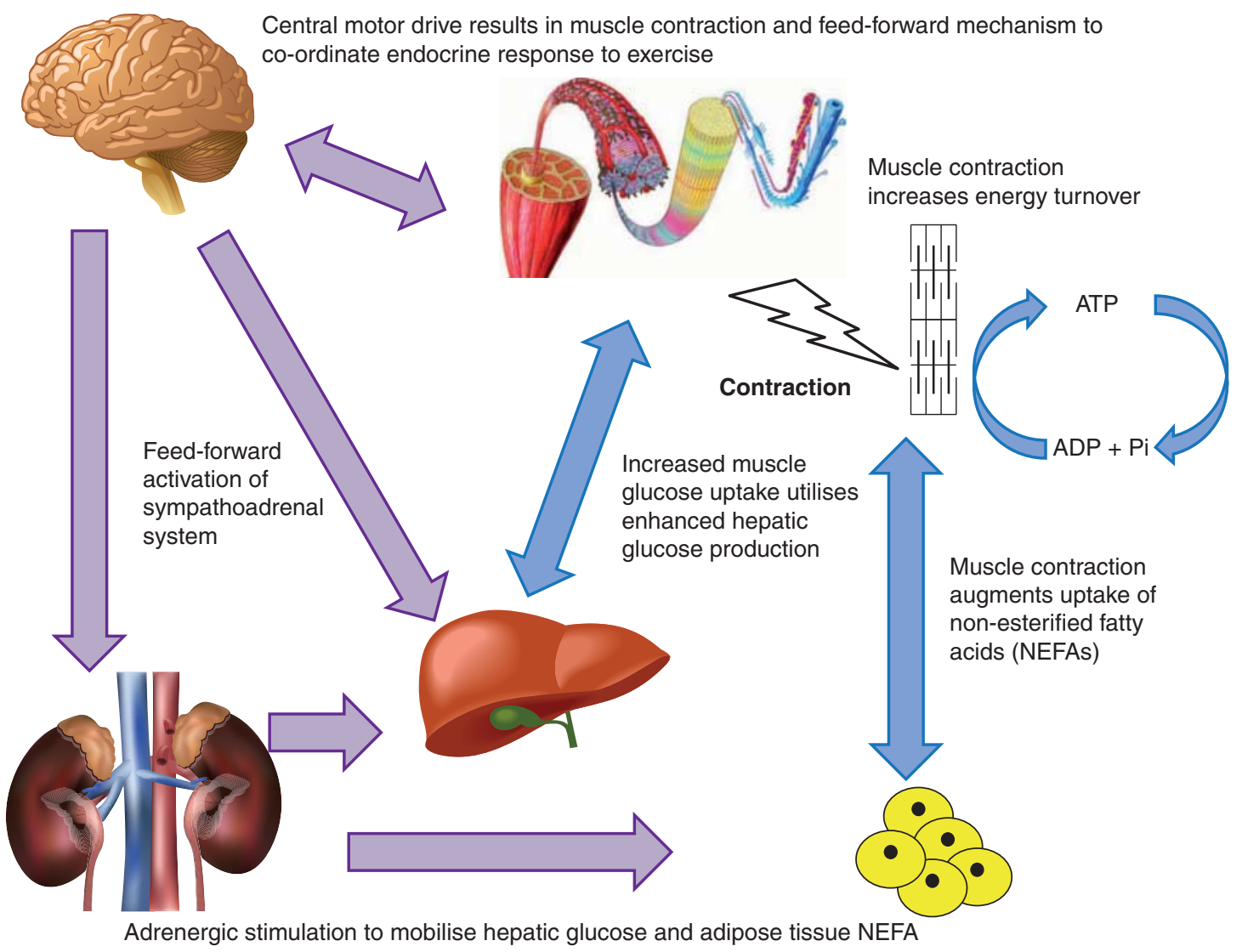

Figure 1

The activation of the CNS to initiate muscle contraction leads to an integrated response from the sympathoadrenal, cardiovascular, hepatic and adipocyte systems to mobilise and deliver oxygen and substrate to maintain energy turnover.

http://joe.endocrinology-journals.org DOI: 10.1530/JOE-14-0408
() 2015 Society for Endocrinology Printed in Great Britain
Published by Bioscientifica Ltd. 
of muscle and adipose tissue as endocrine organs that participate in the co-ordinated endocrine response to exercise stress.

\section{Muscle energetics and the metabolic demands of exercise}

The potential for skeletal muscle to induce metabolic stress is reflected by its capacity to increase resting energy turnover by 1000 times to meet the needs of maximum exercise (Turner \& Hoppler 1999). The concentration of ATP in mixed skeletal muscle is $\sim 25 \mathrm{mmol} / \mathrm{kg}$ of dry muscle (d.m.; Hultman et al. 1967) and in contrast to other intramuscular substrates indicates that ATP is not stored in any large quantity. As a consequence of its limited availability, ATP is resynthesised at a rate for meeting the metabolic demands placed upon the cell. Stimulation of the muscle cell to contract initiates both ATP hydrolysis and resynthesis, and depending on the rate of ATP degradation, the cell will employ different metabolic strategies in an attempt to match the resynthesis rate with the rate of hydrolysis.

During ATP hydrolysis, the free energy that is released is used to generate force, which depending on the external load placed upon the muscle produces force, and shortening in length (concentric contraction), or force but no change in length (isometric contraction) or alternatively, force and a lengthening of muscle (eccentric contraction). The maximum amount of work done by skeletal muscle is reported to be $24 \mathrm{~kJ} / \mathrm{mol}$ of ATP (di Prampero et al. 1988).

The theoretical maximum rate of ATP hydrolysis by myosin ATPase is reported to be $10 \mathrm{mmol} / \mathrm{kg} \mathrm{d}$.m. per s, with the highest rate found to be $\sim 8.6 \mathrm{mmol} / \mathrm{kg} \mathrm{d} . \mathrm{m}$. per $\mathrm{s}$ during isometric contraction (Hultman \& Sjöholm 1983). This rate of ATP breakdown represents $70 \%$ of the total ATP turnover in skeletal muscle, a further $2.4 \mathrm{mmol} / \mathrm{kg}$ d.m. per $\mathrm{s}$ is utilised in the process of $\mathrm{Ca}^{2+}$ and proton handling and the maintenance of $\mathrm{Na}^{+}$and $\mathrm{K}^{+}$balance (Hultman et al. 1987). Other studies (Hultman \& Sjöholm 1983, Bangsbo et al. 2001) have reported a lower rate of ATP hydrolysis and these discrepancies are probably due to the differences in exercise modality, which will have different patterns of motor unit and muscle fibre recruitment. Hydrolysis of ATP leads to an increase in the concentration of ADP, AMP and Pi, although this would reduce the ATP:ADP ratio, the accumulation of these by-products of ATP hydrolysis serves to co-ordinate the metabolic response to exercise by stimulating substrate level and oxidative phosphorylation, the activation of creatine kinase and the expression of AMP-activated protein kinase (AMPK).

The most immediate substrate source for ATP resynthesis in skeletal muscle is phosphocreatine (PCr). Skeletal muscle has sufficient PCr $(\sim 85 \mathrm{mmol} / \mathrm{kg}$ per d.m., Harris et al. (1976)) to sustain the maximum ATP turnover rate for about 7-10 s. In addition to this metabolic pathway, the myokinase reaction utilises ADP to resynthesise ATP with the production of AMP (Spriet et al. 1987). The rise in AMP concentration is now understood to play a key role in activation of AMPK, a metabolic protein that is considered to play a central role in energy sensing in cells (Gowans et al. 2013), although AMP is rapidly deaminated to inosine monophosphate and ammonia through the purine nucleotide cycle (Lowenstein 1972, Meyer \& Terjung 1979).

Not only is $\mathrm{PCr}$ energetically favourable in the resynthesis of ATP but it has a higher concentration than ATP at rest ( $\sim 85 \mathrm{mmol} / \mathrm{kg}$ of d.m., Hultman et al. (1967)). Employing an in-vivo isometric exercise model, Spriet et al. (1987) reported that a $50 \%$ decline in force production coincided with $90 \%$ depletion of $\mathrm{PCr}$, at the same time ATP concentration had decreased by $30 \%$. During exercise, there is sufficient $\mathrm{PCr}$ to sustain the maximum rate of ATP hydrolysis for about 3-5 $\mathrm{s}$ before a decline in power production (Karatzaferi et al. 2001a,b). In this study, muscle biopsy samples revealed that after only $10 \mathrm{~s}$ of maximum power production, the concentration of ATP in the fast contracting muscle fibres had declined by over $30 \%$. These data demonstrate that although skeletal muscle can generate a high power output, there is a limited metabolic capacity to do so.

Skeletal muscle also utilises both fat and carbohydrate as substrates for ATP resynthesis. The rates at which these substrates can resynthesise ATP are significantly lower than that from either PCr or ADP. However, their capacity for ATP resynthesis is significantly greater and consequently there is a trade-off between the power to produce ATP and the capacity for ATP resynthesis. The balance between substrate level phosphorylation (glycolysis) and oxidative phosphorylation (pyruvate and fatty acyl-CoA utilisation) is in part determined by the match between glycolytic flux and mitochondrial respiration. The maximum ATP resynthesis rate from glycogenolysis/glycolysis is reported to be $3.4 \mathrm{mmol} / \mathrm{kg} \mathrm{d}$.m. per s (Hultman \& Spriet 1986) during electrical stimulation of the quadriceps when producing $70-75 \%$ of maximum tetanic force. In contrast, the maximum rate of ATP resynthesis from the utilisation of fatty acids alone is reported to be $\sim 1.0 \mathrm{mmol} / \mathrm{kg} \mathrm{d}$.m. per s (McGilvery 1975; given in Table 1).

Published by Bioscientifica Ltd. 
Table 1 Substrate availability and maximum ATP resynthesis capacity during exercise. Data from McGilvery (1975) and Maughan \& Gleeson (2004)

\begin{tabular}{|c|c|c|}
\hline Metabolic fate & $\begin{array}{c}\text { Intracellular } \\
\text { substrate } \\
\text { availability } \\
\text { (mmol/kg muscle) }\end{array}$ & $\begin{array}{c}\text { Maximum rate } \\
\text { to produce ATP } \\
\text { (mmol/kg dry } \\
\text { matter per s) }\end{array}$ \\
\hline $\mathrm{ATP}, \mathrm{PCr} \rightarrow \mathrm{ADP}, \mathrm{Cr}$ & 32 & 9.0 \\
\hline Glycogen $\rightarrow$ lactate & 240 & 4.5 \\
\hline Glycogen $\rightarrow \mathrm{CO}_{2}, \mathrm{H}_{2} \mathrm{O}$ & 3000 & 2.8 \\
\hline Fatty acids $\rightarrow \mathrm{CO}_{2}, \mathrm{H}_{2} \mathrm{O}$ & $7-25$ & 1.0 \\
\hline
\end{tabular}

As described earlier, there is a trade-off between the power to produce ATP and the capacity for ATP production. Increasing exercise duration is achieved at the expense of the rate of ATP turnover. The lower rate of ATP turnover can be matched by oxidative phosphorylation that employs a combination of glucose/glycogen and fatty acids as the substrates. Early studies demonstrated the balance between fat and carbohydrate oxidation through indirect calorimetry method using expired gases (Christensen \& Hansen 1939, Asmussen 1971). The use of the needle biopsy technique by Bergstrom \& Hultman (1966) permitted direct measurement of intramuscular substrates, primarily glycogen and the glycolytic intermediates. Further studies using muscle biopsies provided a means to delineate the utilisation of glycogen in different muscle fibre populations (Gollnick et al. 1974). These early studies illustrated that utilisation of muscle glycogen was both fibre type and exercise intensity specific. At low exercise intensities (30-45\% $\mathrm{VO}_{2 \max }$ ), glycogen utilisation is primarily confined to type 1 (slow) muscle fibres. However, as the exercise intensity increases so too does the utilisation of glycogen in type 2 (fast) muscle fibres (Fig. 2). Whilst at very high exercise intensities, the rate of glycogen utilisation is also accelerated in type 1 fibres (Greenhaff et al. 1994). Utilisation of intramuscular triglycerides (IMTG) has also been reported, but determining the concentration of this substrate is technically challenging (Van Der Vusse \& Reneman 1996), and there is an ongoing debate concerning the most appropriate method for measuring this substrate. As a consequence, there are limited data, in humans, that directly examines IMTG utilisation during exercise. An alternative method employed to measure the rate of IMTG has been achieved through the use of stable isotopic tracers. Romijn et al. (1993) and Van Loon et al. (2001) demonstrated the reliance on extracellular and intracellular fat and carbohydrates across a range of exercise intensities by employing stable isotope tracers (Fig. 3).

The locus of control for balancing the mix of carbohydrate and fatty acid oxidation is still unresolved, with several candidate mechanism(s) being proposed. In 1963, Randle et al. proposed the 'glucose-fatty acid cycle', which suggested that a reciprocal relationship exists between the availability of fatty acids and glucose and their oxidation. A rise in plasma fatty acid availability, as a function of exercise, was postulated to limit glucose oxidation and increase fat oxidation and vice versa if plasma glucose availability increased with exercise.

Randle et al. (1963) focussed on the effects of fatty acid and ketone body availability because their principle interest was in studying the mechanism of the glucose fatty-acid cycle in relation to diabetes mellitus; however, some of their observations seemed to fit an exercise model and they postulated that increasing ketone body and fatty acid oxidation would inhibit key steps in glycolysis, namely phosphofructokinase (PFK), hexokinase and pyruvate dehydrogenase complex (PDC) activity. In terms of a mechanistic explanation, they argued that altering the acetyl CoA:CoA ratio would inhibit PDC, resulting in an upstream effect on both PFK and hexokinase through citrate and glucose-6-phosphate accumulation. However, the role of citrate, an essential element of the original glucose-fatty acid cycle hypothesis, was brought into question by work that demonstrated that the intracellular level of citrate was not different during intense exercise $\left(85 \% \mathrm{VO}_{2 \max }\right)$ with elevated plasma fatty acids, compared with a control (Dyck et al. 1993). Activation of the PDC through dicholoracetate has demonstrated that pyruvate

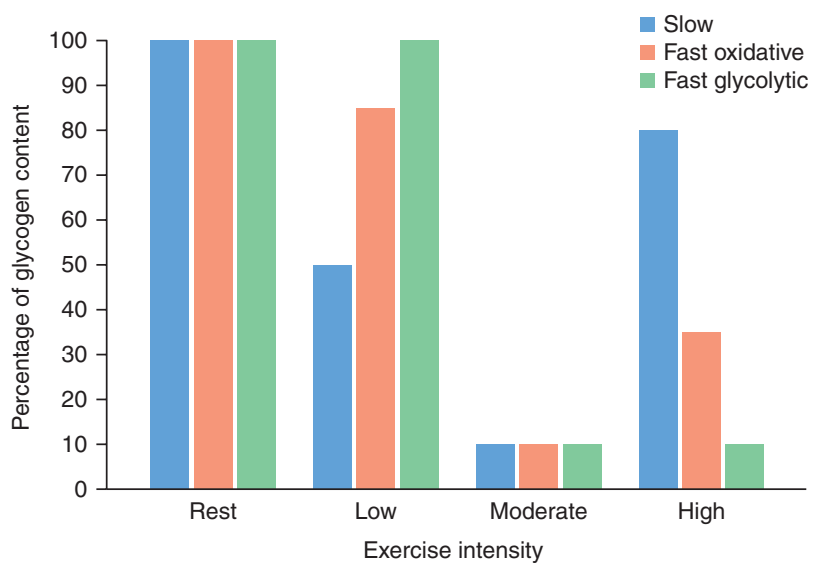

Figure 2

Muscle glycogen utilisation as a function of muscle fibre type and exercise intensity. Data from Gollnick et al. (1974).

Published by Bioscientifica Ltd. 
flux is increased with a concomitant reduction in lactate production and stockpiling of acetyl groups (Timmons et al. 1998), hence any process that inactivates PDC would be expected to decrease carbohydrate oxidation. The availability of carnitine has been suggested as a mechanism that governs the oxidation of carbohydrate and fatty acids as a reduction in free carnitine would limit the transport of fatty acids into the mitochondria (Van Loon et al. 2001, Stephens et al. 2007) and increase the reliance upon carbohydrate. Along a related theme, increases in acetyl-CoA carboxylase (ACC) activity and malonyl CoA concentration and thus inhibition of carnitine palmitoyl transferase 1 have also been proposed as a mechanism that would limit the oxidation of free fatty acids during exercise (Merrill et al. 1998, Båvenholm et al. 2000). However, some studies have observed a decrease in ACC activity and malonyl CoA concentration as a function of exercise/muscle contraction (Rasmussen \& Winder 1997, Dean et al. 2000) that would corroborate a shift to increase fatty acid oxidation, whereas others report no change in malonyl CoA concentration with exercise in humans (Odland et al. 1996). Other putative mechanisms that govern the signalling and transport of non-esterified fatty acids (NEFAs; Bonen et al. 1998) and insulin-independent glucose transport (Ploug et al. 1984, Hargreaves et al. 1991) have been proposed as mechanisms that might limit the intracellular availability of substrate and hence their oxidation. Taken together, these studies highlight the complexity of metabolic integration during exercise in relationship with substrate utilisation and ATP resynthesis.

Substrate utilisation is a product of both exercise intensity and duration. The effects of exercise intensity on substrate utilisation in well-trained cyclists was elegantly demonstrated by Romijn et al. (1993) when employing a stable isotope method to determine the rates of carbohydrate and fat oxidation at exercise intensities that elicited 25,65 and $85 \%$ of maximum oxygen uptake $\left(\mathrm{VO}_{2 \max }\right)$. These authors reported that at $25 \%$ of $\mathrm{VO}_{2 \max }$, the primary contribution to energy turnover was through plasma NEFA utilisation with a smaller but significant contribution from plasma glucose oxidation and little if any contribution from the intramuscular store of glycogen or triglyceride. The metabolic response to exercise at $65 \%$ $\mathrm{VO}_{2 \max }$ resulted in an increase in the utilisation of the intramuscular stores of both glycogen and triglyceride, and it was reported that at this intensity the rate of fat oxidation was higher than either that at 25 or $85 \%$ of $\mathrm{VO}_{2 \max }$. The metabolic response to exercise at $85 \%$ $\mathrm{VO}_{2 \max }$ induced almost a complete reliance on carbohydrate utilisation, whilst there was evidence of some fat oxidation this substrate contributed $<30 \%$ to the total energy turnover. In support of these findings, Van Loon et al. (2001) examined the metabolic response to 30 min of exercise at 40,55 and $75 \%$ of maximal workload (equivalent to 44,57 and $72 \%$ of $\mathrm{VO}_{2 \max }$ ). Again employing stable isotope methods and enhanced by muscle biopsies, they measured intramuscular substrate oxidation and extramuscular substrate provision. Their results supported those of Romijn et al. (1993) but also suggested that at the highest exercise intensity employed that the reduction in fat oxidation could have been due to a limitation in the availability of free carnitine. Collectively, these data demonstrate that at exercise intensities below $30 \%$ of $\mathrm{VO}_{2 \max }$ the principle energy source is fatty acids, between 40 and $65 \%$ of $\mathrm{VO}_{2 \max }$ there is approximately a 50:50 balance between carbohydrate and fat oxidation and beyond $70 \%$ of $\mathrm{VO}_{2 \max }$ there is an exponential rise in carbohydrate oxidation with a concomitant decrease in fat oxidation (see Fig. 3). For a more comprehensive review of fat metabolism during exercise, the reader is referred to Jeukendrup et al. (1998). More recently a metabolomics approach is being adopted to explore the metabolic response to exercise. A wide range of metabolites present in plasma and serum has been determined using liquid chromatography mass spectrometry and/or gas-chromatography mass spectrometry collected pre- and post-exercise. In most cases, a wide range of metabolites have been reported (Pohjanen et al. 2007, Lewis et al. 2010, Peake et al. 2014) to exist and that with exercise changes in metabolites related to carbohydrate, triglyceride and markers of the tricarboxylic acid have been reported.

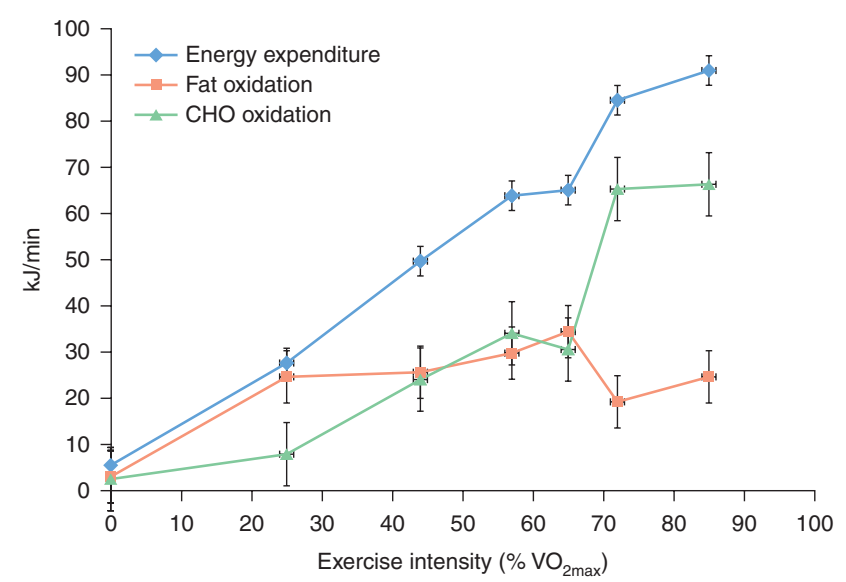

Figure 3

Increasing energy expenditure and the switch in substrate oxidation as a function of exercise intensity. Data taken from Romijn et al. (1993) and Van Loon et al. (2001).

Published by Bioscientifica Ltd. 
Yan et al. (2009) examined the serum metabolite profile in athletes and compared this with healthy age-matched men. They concluded that the profiles of 13 metabolites and analysed using a principal component analysis technique allowed them to differentiate between the athletes and sedentary controls. With the exception of work by Peake et al. (2014), these studies were not hypothesis driven and are more observational in nature. However, the use of metabolomics could provide a unique insight into the co-ordinated metabolic response to exercise in terms of substrate mobilisation, utilisation and the production of metabolic by-products.

Efforts to understand the metabolic response to exercise have centred on how substrate utilisation is matched to ATP turnover and from a historical perspective the current review has presented this literature. Attention has now turned towards the intracellular signalling pathways related to the mechanism of glucose uptake and the expression of glucose transporters (Richter et al. 2003); the expression of differing myosin isoforms and muscle plasticity (Chin 2005); control of protein degradation and synthesis (Baar \& Esser 1999, Hornberger et al. 2001, Parkington et al. 2003) and mitochondrial biogenesis (Wu et al. 1999, Baar et al. 2003), all of which contribute either to ATP hydrolysis or substrate oxidation and ATP resynthesis. Substantial efforts have been taken to clarify the role of AMPK since it was first proposed as the major fuel/energy sensor by Hardie et al. (e.g. Davies et al. 1992, Hawley et al. 1996, Hardie \& Hawley 2001, Jorgensen et al. 2004). In a review of the many processes that AMPK is reported to influence, Hardie (2011) concluded that AMPK regulates all cell function. From the perspective of exercise/muscle contraction, a key element to AMPK activity is the energy charge (ATP:ADP ratio) of the cell, which will change with the onset of contraction. Utilising experimental designs that either increase AMPK activity through administration of AICAR (Jessen et al. 2003) or ablate AMPK expression (Lee-Young et al. 2009), AMPK is now understood to increase skeletal muscle glucose uptake through downstream phosphorylation of Akt/PKB (Cartee \& Wojtaszewski 2007) and increase oxidative phosphorylation by elevating PGC1 $\alpha$ expression (Sasaki et al. 2014) and stimulating fatty acid oxidation through the simultaneous increase in mitochondrial respiration and a decrease in ACC activity (Park et al. 2002, Bonen et al. 2007).

The maintenance of blood glucose during exercise represents a significant challenge because the rate of muscle glucose uptake increases several fold (Ahlborg et al. 1974) and it is a process that is insulin independent
(Ploug et al. 1984). The principle organ for regulating blood glucose is the liver, which in the face of increased blood glucose disposal will increase the rate of hepatic glucose production through glycogen catabolism and gluconeogenesis (Ahlborg et al. 1974, Wahren et al. 1977). Ahlborg \& Felig (1982) reported that during prolonged moderate intensity exercise $\left(\sim 60 \% \mathrm{VO}_{2 \text { max }}\right)$, the rate of hepatic glucose output barely matched the rate of leg glucose uptake during the first $40 \mathrm{~min}$ of exercise. Skeletal muscle was reported to increase glucose uptake greater than tenfold from a resting value of $0.22 \mathrm{mmol} / \mathrm{min}$. Crucially, during the following $140 \mathrm{~min}$, the disparity between hepatic glucose output and leg glucose uptake became wider to the point whereby leg glucose uptake was double that of hepatic glucose production and as a consequence blood glucose had fallen below $3 \mathrm{mmol} / \mathrm{l}$. These findings suggest that the decrease in hepatic glucose output is a function of depletion of the hepatic store of glycogen and that gluconeogenesis is unable to provide glucose at a rate to match the demand of contracting muscle. Increasing exercise intensity is also a potent stimulus to increase both the rate of glucose uptake and the rate of hepatic glucose production (Wahren et al. 1975, Katz et al. 1986). Van Loon et al. (2001) demonstrated that the rate of glucose appearance and disappearance increased as a function of increasing exercise intensity and that at their highest workload $\left(72 \% \mathrm{VO}_{2 \max }\right)$ the rate of plasma glucose oxidation was almost three times that measured at $44 \% \mathrm{VO}_{2 \max }$. The liver plays an important role in the maintenance of euglycaemia, but as these studies indicate the potential for skeletal muscle to utilise extracellular glucose is higher than the maximum rate of hepatic glucose output.

The mobilisation and delivery of endogenous substrates located other than in muscle, primarily glucose derived from the liver and NEFA released from adipose tissue, appear to be under endocrine control. The traditional view is that increasing sympathoadrenal activity, as a function of exercise, results in an increase in glycogen catabolism to release glucose from the liver and triacylgycerol to NEFA and glycerol in adipose tissue. Wahren et al. (1977) and Ahlborg \& Felig (1982) independently reported the effect of increasing exercise intensity on the rate of hepatic glucose release and confirmed that hepatic glucose production increases by sevenfold, as a mechanism to match the rate of muscle glucose uptake that had increased by tenfold. These findings indicate that despite the concerted efforts of the liver to match the rate of skeletal muscle glucose disposal, there is always a deficit and the effects of this during prolonged exercise

Published by Bioscientifica Ltd. 
may result in hypoglycaemia. It is also worth noting that the increase in hepatic glucose occurs despite a 50\% decrease in hepatic blood flow (Wahren et al. 1977).

\section{The endocrine response to exercise}

The complexity and diversity of the entire hormonal response to exercise is too large to be covered in detail in this review. Therefore the context and focus on the metabolic effects of exercise in relationship with the endocrine response will be confined to the sympathoadrenal system. This element of the review will also consider the evidence that skeletal muscle responds to exercise in an endocrine manner by releasing myokines that have been purported to be involved in the mobilisation of extramuscular substrates. For a wider discussion on the hormonal response to exercise, readers are referred to a series of excellent reviews edited by Warren \& Constantini (2000).

The neuroendocrine system controls a plethora of systemic functions that range from metabolism and fluid balance to cardiovascular and pulmonary function, in the context of this review the aim is to examine the endocrine response to exercise in relationship with the maintenance of an increase in energy demand. An early but classic description of the hormonal response to exercise was comprehensively reviewed by Galbo (1983) and similar to the current review substantial focus was devoted to sympathoadrenal activity, metabolism and exercise. The sympathoadrenal system releases the hormones epinephrine, norepinephrine and cortisol, although norepinephrine is often referred to as a hormone more accurately, it acts as a neurotransmitter. When discussing the sympathoadrenal response to various stimuli, it is worth noting that this is frequently reported as the changes in plasma norepinephrine and epinephrine, but that these variables may not precisely reflect the release of norepinephrine from the neuronal terminals of the sympathetic nervous system at the target organ, or methylated norepinephrine (epinephrine) from the chromaffin cells in the adrenal medulla (Galbo 1983, Kjaer \& Lange 2000). However, due to the technical difficulties in directly measuring the release of these neurotransmitter/ hormones, it is widely accepted that any increase or decrease in their plasma concentration indicates a change in sympathoadrenal activity (Galbo 2000).

Increases in sympathetic nervous activity as a function of exercise have been reported to be intrinsically linked to increased activity of the motor cortex of the brain (Kjaer et al. 1987, Victor et al. 1995) and to some degree a metaboreflex from the contracting muscle (Victor et al. 1987). A novel but effective methodology to demonstrate the link between central activation of the motor centre and sympathetic activity is through the use of partial neuromuscular blockade by the i.v. administration of tubocurarine (Kjaer et al. 1987). These authors examined the effects of neuromuscular blockade (assessed as a $25 \%$ reduction in handgrip strength) during submaximal and maximal dynamic exercise. Under control conditions (i.e. no neuromuscular blockade) an increase in exercise intensity from rest to $\sim 55 \% \mathrm{VO}_{2 \max }$ and to that which elicited maximum oxygen uptake $\left(100 \% \mathrm{VO}_{2 \max }\right)$ resulted in a two- and fourfold increase in the plasma norepinephrine and epinephrine concentration respectively. Under partial neuromuscular blockade (curarisation), there was a higher concentration in both norepinephrine and epinephrine at the power output that demanded 55\% $\mathrm{VO}_{2 \max }$ and the volunteers perceived the exercise to be harder. A further consequence of curarisation was that subjects were unable to match the higher power output during the graded exercise test, although their perceived exertion during these trials was no different than the control, but in contrast to the response observed at the lower exercise intensities the plasma epinephrine and norepinephrine concentration was depressed at this higher workload when compared with that found under control conditions. Galbo et al. (1987) reported similar effects of partial neuromuscular blockade (reported as a decrease in handgrip strength of $45 \%$ ) during submaximal and maximal dynamic exercise on the plasma concentration of epinephrine and norepinephrine. Using a different exercise modality, Victor et al. (1995) measured central drive by recording muscle sympathetic activity through the peroneal nerve. They observed that during partial neuromuscular blockade the central drive to try and achieve the same isometric force output was maintained even though force production was only $25 \%$ of that attained under control conditions. The overriding conclusion from these studies is that there is a feed-forward element in terms of activating the sympathoadrenal system as a function of increased activity in the motor cortex of the brain. As mentioned previously, volitional motor unit recruitment initiates a feed-forward response of the sympathoadrenal system that mobilises endogenous substrates. A consequence of this neural-hormonal activity also affects cardiovascular function, which is integrated to the delivery of extracellular substrates for the exercising muscle. The importance of neural control of the circulation was presented in a series of papers published where exercise was the primary experimental

Published by Bioscientifica Ltd. 
model and summarised as furthering our understanding of the role and location of central command (Basnayake et al. 2012, Matsukawa 2012) expanding the role of muscle afferents (Kaufman 2012) and the effects of neural blockade on the pressor response (Secher \& Amann 2012). Owing to the innate potential to increase muscle blood flow by over tenfold from resting muscle conditions, control over blood flow during exercise is essential to avoid compromising central blood volume and pressure (González-Alonso et al. 2008). Sympathetic regulation of muscle blood flow assists in matching oxygen demand and substrate delivery to the exercising muscle whilst simultaneously helping to maintain blood pressure.

The effects of exercise on circulating catecholamine (epinephrine and norepinephrine) release are summarised: exercise induces a rise in catecholamines that is observed across a wide range of exercise modalities (Christensen \& Brandsborg 1973, Galbo et al. 1975, Vecht et al. 1978, Hickson et al. 1979), is exercise-intensity dependent (Galbo et al. 1975, Kjaer et al. 1987) and is diminished with training (Winder et al. 1978, Phillips et al. 1996) and is lower in trained individuals compared with untrained individuals (Bloom et al. 1976, Kjaer \& Galbo 1988). Interpretation of the effects of training status on the sympathoadrenal response to exercise requires careful consideration in relationship to whether the response is based on the absolute workload or is relative to the maximum workload. In general, when based on the absolute workload, the sympathoadrenal response is lower in trained individuals; however, when expressed as a percentage of the maximum workload (i.e. relative workload), trained individuals possess an augmented sympathoadrenal response to exercise.

The effect of increasing exercise intensity on the catecholamine response is an important feature in terms of mobilising both intracellular and extracellular substrates that are required to meet the energetic demands made by the contracting muscle. The exercise-induced increase in catecholamine concentration is of sufficient magnitude to stimulate glycogenolysis in both the liver (Kjaer et al. 1993, Kreisman et al. 2003) and skeletal muscle (Richter et al. 1981, Spriet et al. 1988). Under resting conditions, Chasiotis et al. (1983) demonstrated that infusing epinephrine resulted in an increase in skeletal muscle phosphorylase $a$ and decrease in glycogen synthase I activity with a modest but significant decrease in glycogen content. During exercise, the effects of increasing plasma epinephrine concentration on the metabolism response in muscle is equivocal, with some studies suggesting an increase in carbohydrate utilisation
(Richter et al. 1981, Chasiotis \& Hultman 1985, Jansson et al. 1986, Febbraio et al. 1998) and others reporting no effect (Chesley et al. 1995). The i.v. injection of epinephrine has been shown to accelerate the glycogenolytic rate in type 1 muscle fibres but not type 2 fibres (Greenhaff et al. 1991), which might account for the apparent discrepancy in previous findings because they were based on mixed muscle biopsy data. The effects of adrenergic stimulation on carbohydrate metabolism have also been examined in relationship with glucose uptake by skeletal muscle. Infusion of epinephrine has been reported to decrease glucose uptake (Watt et al. 2001); however, the rate of carbohydrate utilisation was enhanced demonstrating a shift towards intracellular carbohydrate utilisation and away from the utilisation of extracellular glucose. Employing either surgical or pharmaceutical adrenalectomised animal or human models is an interesting experimental approach due to the possibilities afforded by infusing exogenous epinephrine at rates that reflect those observed in normal controls during exercise and comparing the effects with the metabolic response to exercise in their normal (control) state. Kjaer et al. published work evaluating the metabolic response to exercise in adrenalectomised humans (Howlett et al. 1999, Kjaer et al. 2000) and reported that during exercise the adrenalectomised subjects maintained euglycaemia at $\sim 70$ and $\sim 85 \% \mathrm{VO}_{2 \max }$. They also observed that in comparison with age matched controls they maintained the same rate of glycogen utilisation; this despite a lower glycogen phosphorylase a activity. When the adrenalectomised subjects subsequently received an infusion of epinephrine to double that observed in the control subjects the exercise-induced increase in muscle glucose uptake was depressed (Howlett et al. 1999). The effects of epinephrine are not confined to skeletal muscle because a rise in catecholamine concentration coincides with an increase in hepatic glucose output suggesting that the two might be related. Howlett et al. (1999) reported that in adrenalectomised subjects hepatic glucose output was substantially enhanced during the early stages of exercise when receiving an adrenaline infusion and that this effect of an increase in hepatic glucose output resulted in an elevated plasma glucose concentration. However, they also noted that during exercise with the adrenaline infusion, the metabolic clearance rate of glucose was lowered, which would also have an effect of elevating plasma glucose. Kjaer et al. (1993) examined the effects of blockade of the sympathetic nerves innervating the liver and adrenal medulla on the metabolic response to lowand moderate-intensity exercise. Blockade of celiac

Published by Bioscientifica Ltd 
ganglion resulted in a 50\% reduction in plasma epinephrine when compared with the control (no blockade) condition; however, the plasma concentration of norepinephrine was not affected by celiac blockade. When the subjects exercised under conditions of sympathetic blockade, neither the rate of glucose appearance nor disappearance was different when compared with the control condition. The rate of glucose disappearance was higher than glucose appearance, resulting in a decline in plasma glucose during low-intensity exercise and this was not affected by blockade. However, during blockade and infusion with supraphysiological concentrations of epinephrine, they reported that hepatic glucose production increased by $\sim 30 \%$ and this resulted in an elevated plasma concentration of glucose; under these conditions the rate of glucose uptake by skeletal muscle was similar between all conditions. The findings suggest that the plasma concentration of epinephrine or direct innervation of the liver has little effect on hepatic glucose production and that alternative factors may play a role in co-ordinating the release of the hepatic store of carbohydrate.

Adrenergic activation of the receptors on adipose tissue is known to increase the lipolytic rate to liberate NEFAs from stored triacylglycerol (Arner 2005). An increase in circulating epinephrine and nor-epinephrine would therefore be expected to increase NEFA availability. Romijn et al. (1993) reported that the peak oxidation of fatty acids occurred $65 \%$ of $\mathrm{VO}_{2 \max }$ when comparing the effects of exercise intensity at 25,65 and $85 \%$ of $\mathrm{VO}_{2 \max }$ and this metabolic response coincided with an increase in plasma epinephrine concentration. However, at $85 \% \mathrm{VO}_{2 \max }$ the plasma concentration of epinephrine increased further, but the rate of fatty acid oxidation had declined. During the latter stages of intermittent but prolonged $(6 \mathrm{~h})$ of moderate intensity exercise there is a shift in fuel utilisation from carbohydrate to fatty acids (Edwards et al. 1934). Other studies have confirmed these observations and explained the increase in fat utilisation partly as a consequence of the depletion of endogenous carbohydrate stores but also due to a rise in plasma NEFAs (Ahlborg et al. 1974) and this has been positively correlated with an increase in the plasma concentration of epinephrine (Ahlborg \& Felig 1982, Romijn et al. 1993). A rise in plasma epinephrine in itself does not constitute a cause and effect on fatty acid availability, but Arner et al. (1990) demonstrated that during exercise, $\beta$-adrenergic stimulation is the principle mechanism for activating lipolysis in adipose tissue. Infusion of epinephrine has been shown to stimulate an increase in NEFAs during low-intensity exercise $\left(40 \% \mathrm{VO}_{2 \max }\right.$; Mora-Rodriguez \&
Coyle 2000). Despite the increased availability of fatty acids, the rate of fat oxidation remained unchanged thus providing further evidence of a limitation in substrate utilisation despite an increase in substrate availability, as previously discussed.

Under resting conditions, the rate of glucose uptake by skeletal muscle is $\sim 0.2 \mathrm{mmol} / \mathrm{min}$ (Ahlborg \& Felig 1982). It is postulated that the presence of the GLUT1 transporter is the mechanism responsible for the baseline rate of glucose uptake (Ciaraldi et al. 2005) and in the postabsorptive state is insulin independent. At rest, a rise in plasma insulin concentration results in an increase in glucose uptake into muscle through insulin-stimulated GLUT4 transport (James et al. 1988) and an inhibition in hepatic glucose production (DeFronzo et al. 1981). Exercise reduces circulating insulin concentration (Ahlborg et al. 1974, Hilsted et al. 1981, Galbo 1983), but as discussed earlier the rate of muscle glucose uptake can increase by tenfold during exercise. The link between exerciseinduced skeletal muscle glucose uptake and an increase in GLUT4 expression demonstrates that there is an insulinindependent mechanism for increasing glucose transport (Ploug et al. 1992). It has been established that rises in contraction-induced AMP and increased AMPK activity result in a signalling cascade to increase the expression of GLUT4 at the sarcolemmal membrane and hence increase glucose uptake (Richter \& Hargreaves 2013).

In the post-absorptive state, euglycaemia is maintained through a steady state hepatic output of glucose that is mediated through glucagon, stimulating both glycogenolysis and gluconeogenesis (Stevenson et al. 1987). Owing to the reciprocal nature of insulin and glucagon release, one would expect the concentration of glucagon to increase during exercise. Galbo et al. (1975) reported that a $35 \%$ rise in glucagon concentration was positively correlated with an increase in exercise intensity, from $\sim 45$ to $100 \% \mathrm{VO}_{2 \max }$; however, Wahren et al. (1977) reported that plasma glucagon concentration did not change from rest when exercising at $60 \% \mathrm{VO}_{2 \max }$ for $40 \mathrm{~min}$. The duration of exercise appears to be an important factor in the stimulation of glucagon release because Galbo et al. (1975) observed that plasma glucagon increased threefold during the later stages of exercise at $70 \% \mathrm{VO}_{2 \max }$. The metabolic effects of increasing glucagon concentration during exercise appear to be confined to the liver (Wasserman et al. 1989, Wasserman \& Cherrington 1991) and there are no studies, to the authors' knowledge, that demonstrate a direct effect of glucagon on lipolysis during exercise. Overall, an increase in contractile activity of muscle will accelerate the rate of glucose uptake and

Published by Bioscientifica Ltd. 
in an effort to maintain euglycaemia hepatic glucose production is accelerated through an increase in glycogenolysis and gluconeogenesis.

Exercise also leads to an increase in the production and release of growth hormone, testosterone, adrenocorticotrophic hormone, cortisol and prolactin that each has local and systemic effects. However, discussing the scope of the effects of changing these hormones on factors such as muscle growth and repair is beyond the scope of this review and the reader is referred to the following papers (Galbo 2000, Kjaer \& Lange 2000, Crewther et al. 2011).

\section{The effect of exercise on cytokine expression}

Based upon the increases in circulating catecholamines (epinephrine, norepinephrine and cortisol), increases in cell numbers related to the immune system (white blood cells) and an acute inflammatory response, i.e. an increase in cytokines (such as interleukin 6 (IL6), IL10 and tumournecrosing factor alpha) the metabolic challenge presented by exercise could be viewed as a stress response. The initial interpretation of the exercise-induced increases in white blood cell number was thought to be due to a systemic inflammatory response or due to exercise-induced muscle damage (Brenner et al. 1999, Fischer 2006). Interest in the systemic role of cytokine expression has gathered pace since the early observation that the circulating cytokine concentration increases after moderate prolonged exercise (Fischer 2006). The pleiotropic result of increasing cytokine concentration appears to be mediated through either a chronic or acute stimulus that induces a pro-inflammatory or anti-inflammatory outcome. Comparisons between the increases in circulating cytokines associated with sepsis with those following exercise have been made with the conclusion that the magnitude and temporal pattern of cytokine expression differs and is dependent on whether the stimulus is through infection or exercise (see Fig. 4, Pedersen \& Febbraio 2008). Separate observations on the expression of cytokines in relationship with disease status have also attracted interest due to the reported elevated plasma cytokine IL6 expression observed in type 2 diabetic patients (Kristiansen \& Mandrup-Poulsen 2005). The causal link between IL6 expression and glucose/carbohydrate metabolism and exercise has yet to be fully established; however, there is a growing interest in the link between the two (Kristiansen \& Mandrup-Poulsen 2005, Franckhauser et al. 2008, Sarvas et al. 2013).

From the perspective of an inflammatory response to exercise, the focus of attention has centred on the increase
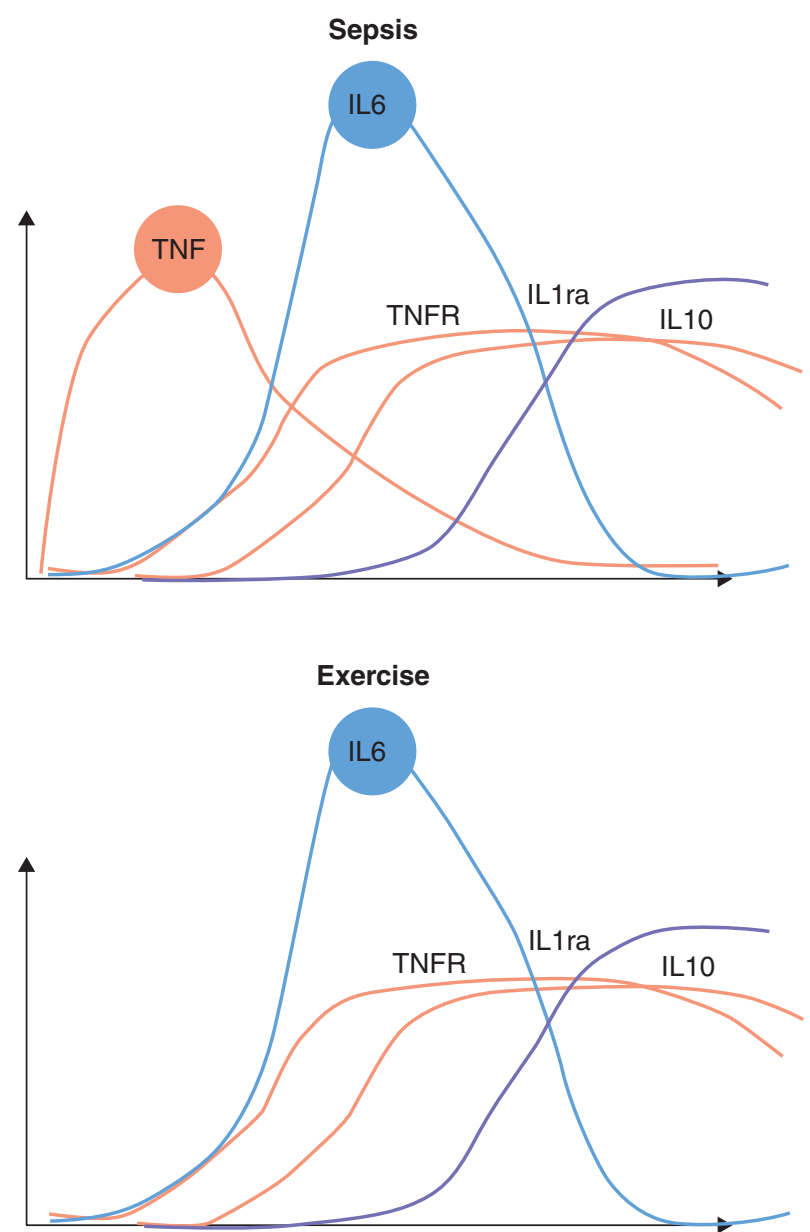

Figure 4

The effects of sepsis and exercise on cytokine expression, note that the magnitude of effect differs between stimulus. Figure from Pedersen \& Febbraio (2008).

of the inflammatory cytokine, IL6, as a function of exercise (see Figs 4 and 5, Li \& Gleeson 2004, Fischer 2006, Pedersen \& Fischer 2007). It has been suggested that muscle may release secretory factors related to contractile activity that have systemic effects (Pedersen \& Febbraio 2008). Several review papers that examined the evidence for an endocrine role of skeletal muscle (Pedersen $e t$ al. 2007) have been published and concluded that skeletal muscle expresses several myokines including IL6, IL8 and IL10 (Pedersen et al. 2001, Febbraio \& Pedersen 2005, Pedersen 2009). There are numerous papers supporting an increase in IL6 expression with exercise but relatively fewer investigations reporting a relationship between IL10 and exercise (Nieman et al. 2006, Ropelle et al. 2010). Fischer (2006) conducted a systematic review of the relationship between exercise and IL6 expression. Of the 65 studies that Fischer reviewed, eight employed a

Published by Bioscientifica Ltd. 


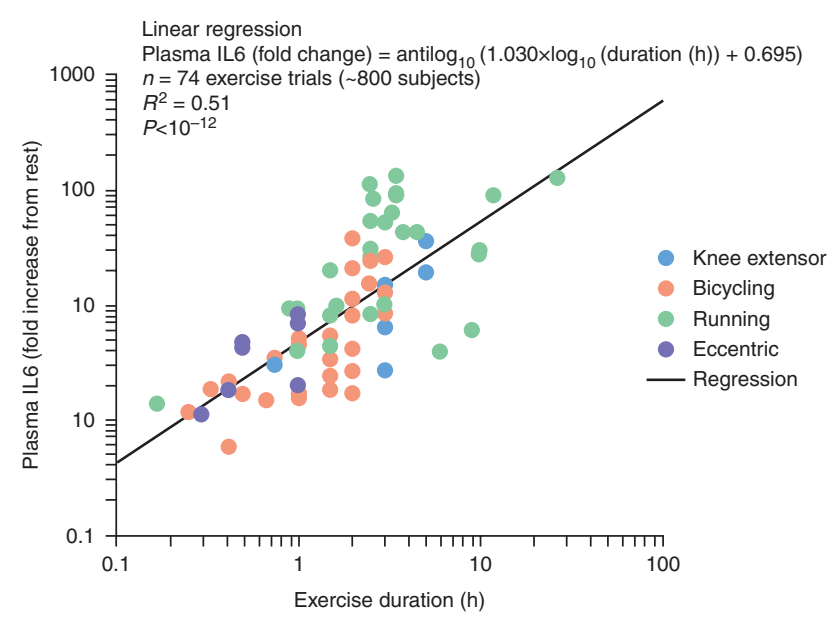

Figure 5

IL6 expression increases as a function of exercise duration. Figure from Fischer (2006).

single-leg knee extensor exercise mode, 30 utilised cycling and the remaining 27 used running as the exercise modality. The increase in IL6 expression varied between a onefold increase and a 128-fold increase, with the higher levels of IL6 expression generally observed as a function of the longer duration of exercise. Whilst this may seem a prodigious increase in IL6 expression due to exercise, severe infection induced can result in levels of circulating IL6 that are up to ten times higher, i.e. a 1000-fold increase from basal levels (Friedland et al. 1992). The mode of exercise also appears to be important in determining the IL6 response with running resulting in the highest level of IL6 expression (Fischer 2006). While it should be noted that the duration of exercise tended to be longer in the running studies; two experiments, Nieman et al. (1998) and Starkie et al. (2001) employed both running and cycling and reported higher levels of IL6 expression when running was completed by subjects compared with cycling, despite the fact that the exercise was at the same relative intensity and for the same duration.

The source of the increased circulating IL6 continues to be a source of debate since it is known that circulating monocytes release IL6 (Gleeson 2000). However, Starkie et al. (2001) reported that despite a marked increase in circulating white cell number following completion of a marathon $(42.2 \mathrm{~km})$, the number of cells producing the cytokines IL1 and IL6 decreased, suggesting that white blood cells are not the source of IL6 following exercise. An early study examining the effects of prolonged exercise on cytokine expression suggested that the source of IL6 may stem from skeletal muscle (Ostrowski et al. 1998).
They reported that $60 \%$ of the participants exhibited an increase in mRNA expression of IL6 in muscle; however, the method of measuring mRNA was semi-quantitative. A later report from the same group (Steensberg et al. 2000) measured the release of IL6 from human contracting muscle by determining the femoral vein-arterial difference and demonstrated, for the first time, that IL6 is released by exercising muscle. Whilst the strong evidence from this study demonstrates that skeletal muscle releases cytokines, the actual source of IL6 was not identified and as highlighted by Gleeson (2000) there are numerous types of cells that could account for the production of IL6. The evidence for skeletal muscle as the principle source of IL6 release appears to be strong but other cell types, such as endothelial cells, connective tissue, adipose tissue, interstitial macrophages may also contribute to the release of cytokines.

One factor that appears to be important in an exercise-induced cytokine release is a reduction in the availability of intramuscular glycogen. Almost all studies that have measured the circulating concentration of IL6 report that depleting the intramuscular store of glycogen before exercise augments the circulating IL6 concentration (Nehlsen-Cannarella et al. 1997, Bishop et al. 2001, Keller et al. 2001, Steensberg et al. 2001, MacDonald et al. 2003). Gleeson et al. (1998) reported a significant increase in white cell count and granulocyte activity following prolonged submaximal exercise and that this response was augmented when preceded by the consumption of a diet low in carbohydrate. In a follow-up study, they also measured the plasma cytokine concentration and reported that in a glycogen depleted state there was an increase in the plasma concentration of cortisol and IL1r, IL6 and IL10 expression in the first hour following strenuous exercise (Bishop et al. 2001). The proposition that carbohydrate availability is linked with cytokine expression is further strengthened by the observation that the provision of exogenous carbohydrate has a suppressive effect on plasma IL6 concentration (Nieman et al. 1998, Febbraio et al. 2003). The activity of AMPK has been proposed as an intracellular signal that governs skeletal muscle cytokine expression (Weigert et al. 2007), but another study suggests that AMPK activity is increased by IL6 (Yuen et al. 2009). Furthermore, Lihn et al. (2008) reported that cytokine expression is reduced by AMPK activity. Clearly, the energy status of the cell, in terms of substrate availability and intracellular signalling, is linked to cytokine expression but exact the nature of the relationship is still not fully understood.

Published by Bioscientifica Ltd. 
It has been postulated that IL6 release is associated with the mobilisation of extracellular substrates. Febbraio et al. (2004) examined the effects of administering recombinant human IL6 (rh-IL6) during $2 \mathrm{~h}$ of lowintensity exercise $\left(40 \% \mathrm{VO}_{2 \max }\right)$. Using stable isotope tracer techniques, to determine hepatic glucose production (Ra) and rate of glucose disposal (Rd), they reported that infusion of rh-IL6 resulted in an increase in both $\mathrm{Ra}$ and $\mathrm{Rd}$ when compared with low-intensity exercise alone. They also compared the metabolic effects of rhIL6 at low-intensity exercise with exercise at $70 \%$ $\mathrm{VO}_{2 \max }$. Despite the fact that Ra and Rd were not different between low-intensity exercise with rhIL6 and exercise at $70 \% \mathrm{VO}_{2 \max }$, the metabolic clearance rate of glucose was higher during exercise at $70 \% \mathrm{VO}_{2 \max }$. In support of the role of IL6 in promotion of skeletal muscle glucose uptake Glund et al. (2007) reported that IL6 increased in vitro skeletal muscle glucose uptake by 1.3 -fold, a prodigious improvement in glucose transport; however, the concentration of IL6 used in the study was supraphysiological. Other observations, however, have been unable to demonstrate any effect of IL6 on hepatic glucose output (Wolsk et al. 2010). Any increase in plasma glucose following the administration of recombinant IL6 could also be due to a decline in skeletal muscle glucose uptake rather than an increase in hepatic glucose output. Increasing the plasma concentration of IL6 has been linked to an increase in plasma non-esterified concentration according to Wolsk et al. (2010). Examining the effects of rhIL6 they reported that following IL6 infusion both the rate of palmitate appearance and oxidation increased when compared with a saline infusion. Taken together, these effects of IL6 suggest some augmentation of the sympathoadrenal system, as it has been shown that an increase in catecholamine release during exercise results in an increase in lipolysis (Arner 2005) with the effects of IL6 resulting in a similar increase in NEFA availability.

\section{Conclusion}

Skeletal muscle can increase the rate of energy turnover from rest to maximum force/power output that requires an integrated response both from within the cell and systemically to match the rate of ATP degradation with the ATP resynthesis. The metabolic co-ordination required to do this incorporates the demand on different substrates to maintain ATP production to support muscle contraction. In addition, the sympathetic system is activated in a feedforward manner by the motor centre in the brain with the consequence of initiating an endocrine response to exercise as reflected by the increases in sympathoadrenal activity. Focus has now switched to the role that skeletal muscle plays in a systemic endocrine response that appears to be related to substrate availability within the exercising muscle. The equivocal role of cytokine expression during and after exercise and the contrasting effects to cytokine expression related to disease remain a fertile area for research.

\section{Declaration of interest}

The author declares that there is no conflict of interest that could be perceived as prejudicing the impartiality of this review.

\section{Funding}

This review did not receive any specific grant from any funding agency in the public, commercial or not-for-profit sector.

\section{Acknowledgements}

The author wishes to thank Drs A Strachan and G Smith for valuable comments made on drafts of this manuscript.

\section{References}

Ahlborg G \& Felig P 1982 Lactate and glucose exchange across the forearm, legs, and splanchnic bed during and after prolonged leg exercise. Journal of Clinical Investigation 69 45-54. (doi:10.1172/JCI110440)

Ahlborg G, Felig P, Hagenfeldt L, Hendler R \& Wahren J 1974 Substrate turnover during prolonged exercise in man: splanchnic and leg metabolism of glucose, free fatty acids and amino acids. Journal of Clinical Investigation 53 1080-1090. (doi:10.1172/JCI107645)

Arner P 2005 Human fat cell lipolysis: biochemistry, regulation and clinical role. Best Practice \& Research. Clinical Endocrinology \& Metabolism 19 471-482. (doi:10.1016/j.beem.2005.07.004)

Arner P, Kriegholm E, Engfeldt P \& Bolinder J 1990 Adrenergic regulation of lipolysis in situ at rest and during exercise. Journal of Clinical Investigation 85 893-898. (doi:10.1172/JCI114516)

Asmussen E 1971 Muscle metabolism during exercise in man: a historical survey. In Muscle Metabolism During Exercise, pp 1-12. Eds B Pernow \& B Saltin. New York: Plenum Press.

Baar K \& Esser K 1999 Phosphorylation of p70(S6k) correlates with increased skeletal muscle mass following resistance exercise. American Journal of Physiology. Cell Physiology 276 C120-C127.

Baar K, Song Z, Semenkovich CF, Jones TE, Han DH, Nolte LA, Ojuka EO, Chen M \& Holloszy JO 2003 Skeletal muscle overexpression of nuclear respiratory factor 1 increases glucose transport capacity. FASEB Journal 17 1666-1673. (doi:10.1096/fj.03-0049com)

Bangsbo J, Krustrup P, Gonzalez-Alonso J \& Saltin B 2001 ATP production and efficiency of human skeletal muscle during intense exercise: effect of previous exercise. American Journal of Physiology 280 E956-E964.

Basnayake SD, Green AL \& Paterson DJ 2012 Mapping the central neurocircuitry that integrates the cardiovascular response to exercise in humans. Experimental Physiology 97 29-38. (doi:10.1113/expphysiol. 2011.060848) http://joe.endocrinology-journals.org DOI: $10.1530 / \mathrm{JOE}-14-0408$
() 2015 Society for Endocrinology Printed in Great Britain 
Båvenholm PN, Pigon J, Saha AK, Ruderman NB \& Efendic S 2000 Fatty acid oxidation and the regulation of malonyl-CoA in human muscle. Diabetes 49 1078-1083. (doi:10.2337/diabetes.49.7.1078)

Bergstrom J \& Hultman E 1966 Muscle glycogen synthesis after exercise. An enhancing factor localized to the muscle cells in man. Nature $\mathbf{2 1 0}$ 209-310. (doi:10.1038/210209a0)

Bishop NC, Walsh NP, Haines DL, Richards EE \& Gleeson M 2001 Preexercise carbohydrate status and hormone responses to prolonged cycling: II. Effect on plasma cytokine concentration. International Journal of Sport Nutrition and Exercise Metabolism 11 503-512.

Bloom SR, Johnson RH, Park DM, Rennie MJ \& Sulaiman WR 1976 Differences in the metabolic response and hormonal response to exercise between racing cyclists and untrained individuals. Journal of Physiology 258 1-18.

Bonen A, Dyck DJ, Ibrahimi A \& Abumrad NA 1998 Muscle contractile activity increases fatty acid metabolism and transport and FAT/CD36. American Journal of Physiology. Endocrinology and Metabolism 276 E642-E649.

Bonen A, Han X-X, Habets DD, Febbraio M, Glatz JF \& Luiken JJ 2007 A null mutation in skeletal muscle FAT/CD36 reveals its essential role in insulin- and AICAR-stimulated fatty acid metabolism. American Journal of Physiology. Endocrinology and Metabolism 292 E1740-E1749. (doi:10.1152/ajpendo.00579.2006)

Borghouts LB \& Keizer HA 2000 Exercise and insulin sensitivity: a review. International Journal of Sports Medicine 21 1-12. (doi:10.1055/s2000-8847)

Brenner IK, Natale VM, Vasiliou P, Moldoveanu AI, Shek PN \& Shephard RJ 1999 Impact of three different types of exercise on components of the inflammatory response. European Journal of Applied Physiology $\mathbf{8 0}$ 452-460. (doi:10.1007/s004210050617)

Cartee GD \& Wojtaszewski JF 2007 Role of Akt substrate of $160 \mathrm{kDa}$ in insulin-stimulated and contraction-stimulated glucose transport. Applied Physiology, Nutrition, and Metabolism 32 557-566. (doi:10.1139/ H07-026)

Chasiotis D \& Hultman E 1985 Epinephrine infusion enhances muscle glycogenolysis during prolonged electrical stimulation. Acta Physiologica Scandinavica 123 55-60. (doi:10.1111/j.1748-1716.1985. tb07560.x)

Chasiotis D, Sahlin K \& Hultman E 1983 Regulation of glycogenolysis in human muscle in response to epinephrine infusion. Journal of Applied Physiology 54 45-50.

Chesley A, Hultman E \& Spriet LL 1995 Effects of epinephrine infusion on muscle glycogenolysis during intense aerobic exercise. American Journal of Physiology. Endocrinology and Metabolism 268 E127-E134.

Chin ER 2005 Role of $\mathrm{Ca}^{2+} /$ calmodulin-dependent kinases in skeletal muscle plasticity. Journal of Applied Physiology 99 414-423. (doi:10.1152/japplphysiol.00015.2005)

Christensen NJ \& Brandsborg O 1973 The relationship between plasma catecholamine concentration and pulse rate during exercise and standing. European Journal of Clinical Investigation 3 299-306. (doi:10.1111/j.1365-2362.1973.tb00355.x)

Christensen EH \& Hansen O 1939 111. Arbeitfahigkeit und Ernahrung. Skandinavisches Archiv Für Physiologie 81 160-171.

Ciaraldi TP, Mudaliar S, Barzin A, Macievic JA, Edelman SV, Park KS \& Henry RR 2005 Skeletal muscle GLUT1 transporter protein expression and basal leg glucose uptake are reduced in type 2 diabetes. Journal of Clinical Endocrinology and Metabolism 90 352-358. (doi:10.1210/jc. 2004-0516)

Crewther BT, Cook C, Cardinale M, Weatherby RP \& Lowe T 2011 Two emerging concepts for elite athletes: the short-term effects of testosterone and cortisol on the neuromuscular system and the dose-response training role of these endogenous hormones. Sports Medicine 41 103-123. (doi:10.2165/11539170-000000000-00000)

Davies SP, Carling D, Munday MR \& Hardie DG 1992 Diurnal rhythm of phosphorylation of rat liver acetyl-CoA carboxylase by the AMPactivated protein kinase, demonstrated using freeze-clamping. Effects of high fat diets. European Journal of Biochemistry 203 615-623. (doi:10.1111/j.1432-1033.1992.tb16591.x)

Dean D, Daugaard JR, Young ME, Saha A, Vavvas D, Asp S, Kiens B, Kim KH, Witters L, Richter EA et al. 2000 Exercise diminishes the activity of acetyl-CoA carboxylase in human muscle. Diabetes 49 1295-1300. (doi:10.2337/diabetes.49.8.1295)

Defronzo RA, Jacot E, Jequier E, Maeder E, Wahren J \& Felber JP 1981 The effect of insulin on the disposal of intravenous glucose results from indirect calorimetry and hepatic and femoral venous catheterization. Diabetes 30 1000-1007. (doi:10.2337/diab.30.12.1000)

Di Prampero PE, Boutellier U \& Marguerat A 1988 Efficiency of work performance and contraction velocity in isotonic tetani of frog sartorius. Pflügers Archiv: European Journal of Physiology 412 455-461. (doi:10.1007/BF00582533)

Dyck DJ, Putman CT, Heigenhauser GJ, Hultman E \& Spriet LL 1993 Regulation of fat-carbohydrate interaction in skeletal muscle during intense aerobic cycling. American Journal of Physiology. Endocrinology and Metabolism 265 852-859.

Edwards HT, Margaria R \& Dill DB 1934 Metabolic rate, blood sugar and the utilization of carbohydrate. American Journal of Physiology 108 203-209.

Febbraio MA \& Pedersen BK 2005 Contraction-induced myokine production and release: is skeletal muscle an endocrine organ? Exercise and Sport Sciences Reviews 33 114-119. (doi:10.1097/00003677200507000-00003)

Febbraio MA, Lambert DL, Starkie RL, Proietto J \& Hargreaves M 1998 Effect of epinephrine on muscle glycogenolysis during exercise in trained men. Journal of Applied Physiology $\mathbf{8 4} 465-470$.

Febbraio MA, Steensberg A, Keller C, Starkie RL, Nielsen HB, Krustrup P, Ott P, Secher NH \& Pedersen BK 2003 Glucose ingestion attenuates interleukin-6 release from contracting skeletal muscle in humans. Journal of Physiology 549 607-612. (doi:10.1113/jphysiol.2003.042374)

Febbraio MA, Hiscock N, Sacchetti M, Fischer CP \& Pedersen BK 2004 Interleukin- 6 is a novel factor mediating glucose homeostasis during skeletal muscle contraction. Diabetes 53 1643-1648. (doi:10.2337/ diabetes.53.7.1643)

Fischer CP 2006 Interleukin-6 in acute exercise and training: what is the biological relevance? Exercise Immunology Review 12 6-33.

Franckhauser S, Elias I, Rotter Sopasakis V, Ferré T, Nagaev I, Andersson CX, Agudo J, Ruberte J, Bosch F \& Smith U 2008 Overexpression of Il6 leads to hyperinsulinaemia, liver inflammation and reduced body weight in mice. Diabetologia 51 1306-1316. (doi:10.1007/s00125-008-0998-8)

Friedland JS, Suputtamongkol Y, Remick DG, Chaowagul W, Strieter RM, Kunkel SL, White NJ \& Griffin GE 1992 Prolonged elevation of interleukin-8 and interleukin- 6 concentrations in plasma and of leukocyte interleukin-8 mRNA levels during septicemic and localized Pseudomonas pseudomallei infection. Infection and Immunity $\mathbf{6 0}$ 2402-2408.

Galbo H 1983 In Hormonal and Metabolic Adaptation to Exercise. Stuttgart, Germany: Thieme.

Galbo H 2000 Endocrine factors in endurance. In Endurance in Sport, pp 116-126. Eds RJ Shephard \& P-O Astrand. Oxford: Blackwell Scientific.

Galbo H, Holst JJ \& Christensen NJ 1975 Glucagon and plasma catecholamine responses to graded and prolonged exercise in man. Journal of Applied Physiology 38 70-76.

Galbo H, Kjaer M \& Secher NH 1987 Cardiovascular, ventilatory and catecholamine responses to maximal dynamic exercise in partially curarized man. Journal of Physiology 389 557-568.

Gleeson M 2000 Interleukins and exercise. Journal of Physiology 5291. (doi:10.1111/j.1469-7793.2000.00001.x)

Gleeson M, Blannin AK, Walsh NP, Bishop NC \& Clark AM 1998 Effect of low- and high-carbohydrate diets on the plasma glutamine and circulating leukocyte responses to exercise. International Journal of Sport Nutrition 8 49-59.

Glund S, Deshmukh A, Long YC, Moller T, Koistinen HA, Caidahl K, Zierath JR \& Krook A 2007 Interleukin-6 directly increases glucose 
metabolism in resting human skeletal muscle. Diabetes 56 1630-1637. (doi:10.2337/db06-1733)

Gollnick PD, Piehl K \& Saltin B 1974 Selective glycogen depletion pattern in human muscle fibres after exercise of varying intensity and at varying pedaling frequency. Journal of Physiology 241 45-57.

González-Alonso J, Crandall CG \& Johnson JM 2008 The cardiovascular challenge of exercising in the heat. Journal of Physiology 586 45-53. (doi:10.1113/jphysiol.2007.142158)

Gowans G, Hawley SA, Ross FA \& Hardie G 2013 AMP is a true physiological regulator of AMP-activated protein kinase by both allosteric activation and enhancing net phosphorylation. Cell Metabolism 18 556-566. (doi:10.1016/j.cmet.2013.08.019)

Goyaram V, Kohn TA \& Ojuka EO 2014 Suppression of the GLUT4 adaptive response to exercise in fructose-fed rats. American Journal of Physiology. Endocrinology and Metabolism 306 E275-E283. (doi:10.1152/ajpendo. 00342.2013)

Greenhaff PL, Ren J-M, Söderlund K \& Hultman E 1991 Energy metabolism in single human muscle fibers during contraction without and with epinephrine infusion. American Journal of Physiology. Endocrinology and Metabolism 260 E713-E718.

Greenhaff PL, Nevill ME, Soderland K, Bodin K, Boobis LH, Williams C \& Hultman E 1994 The metabolic responses of human type I and II muscle fibres during maximal treadmill sprinting. Journal of Physiology 478 149-155.

Hardie DG 2011 AMP-activated protein kinase: an energy sensor that regulates all aspects of cell function. Genes and Development 25 1895-1908. (doi:10.1101/gad.17420111)

Hardie DG \& Hawley SA 2001 AMP-activated protein kinase: the energy charge hypothesis revisited. BioEssays 23 1112-1119. (doi:10.1002/ bies.10009)

Hargreaves M, Kiens B \& Richter EA 1991 Effect of increased plasma free fatty acid concentrations on muscle metabolism in exercising men. Journal of Applied Physiology 70 194-201.

Harris RC, Edwards RHT, Hultman E, Nordesjo LO, Nylind B \& Sahlin K 1976 The time course of phosphorylcreatine resynthesis during recovery of the quadriceps muscle in man. Pflügers Archiv: European Journal of Physiology 367 137-142. (doi:10.1007/BF00585149)

Hawley SA, Davison M, Woods A, Davies SP, Beri RK, Carling D \& Hardie DG 1996 Characterization of the AMP-activated protein kinase kinase from rat liver, and identification of threonine- 172 as the major site at which it phosphorylates and activates AMP-activated protein kinase. Journal of Biological Chemistry 271 27879-27887. (doi:10.1074/jbc.271. 44.27879)

Heady JA, Morris JN, Kagan A \& Raffle PAB 1961 Coronary heart disease in London busmen: a progress report with particular reference to physique. British Journal of Preventive and Societal Medicine 15 143-153.

Henderson GC \& Alderman BL 2014 Determinants of resting lipid oxidation in response to a prior bout of endurance exercise. Journal of Applied Physiology 116 95-103. (doi:10.1152/japplphysiol.00956.2013)

Hickson RC, Hagberg JM, Conlee RK, Jones DA, Ehsani AA \& Winder WW 1979 Effect of training on hormonal responses to exercise in competitive swimmers. European Journal of Applied Physiology $\mathbf{4 1}$ 211-219. (doi:10.1007/BF00430013)

Hilsted J, Galbo H, Tonier B, Christensen NJ \& Schwartz TW 1981 Hormonal and metabolic responses to exercise in insulin-dependent diabetics with and without autonomic neuropathy and in normal subjects. International Journal of Sports Medicine 2 216-219. (doi:10.1055/s-2008-1034612)

Hornberger TA, Hunter RB, Kandarian SC \& Esser KA 2001 Regulation of translation factors during hindlimb unloading and denervation of skeletal muscle in rats. American Journal of Physiology. Cell Physiology 281 C179-C187.

Howlett K, Galbo H, Lorentsen J, Bergeron R, Zimmerman-Belsing T, Bulow J, Feldt-Rasmussen U \& Kjaer M 1999 Effect of adrenaline on glucose kinetics during exercise in adrenalectomised humans. Journal of Physiology 519 911-921. (doi:10.1111/j.1469-7793.1999.0911n.x)
Hultman E \& Sjöholm H 1983 Energy metabolism and contraction force of human skeletal muscle in situ during electrical stimulation. Journal of Physiology 345 525-532.

Hultman E \& Spriet LL 1986 Skeletal muscle metabolism, contraction force and glycogen utilization during prolonged electrical stimulation in humans. Journal of Physiology $\mathbf{3 7 4} 493-501$.

Hultman E, Bergstrom J \& McLennan-Anderson N 1967 Breakdown and resynthesis of phosphorylcreatine and adenosine triphosphate in connection with muscular work in man. Scandinavian Journal of Clinical and Laboratory Investigation 19 56-66. (doi:10.3109/ $00365516709093481)$

Hultman E, Spriet L \& Söderland K 1987 Energy metabolism and fatigue in working muscle. In Benefits, limits and adaptations, pp 63-84. Eds D Macleod, R Maughan, M Nimmo, T Reilly \& C Williams. London, UK: E \& F N Spon.

James DE, Brown R, Navarro J \& Pilch PF 1988 Insulin-regulatable tissues express a unique insulin-sensitive glucose transport protein. Nature $\mathbf{3 3 3}$ 183-185. (doi:10.1038/333183a0)

Jansson E, Hjemdahl P \& Kaijser L 1986 Epinephrine-induced changes in muscle carbohydrate metabolism during exercise in male subjects. Journal of Applied Physiology 60 1466-1470.

Jessen N, Pold R, Buhl ES, Jensen LS, Schmitz O \& Lund S 2003 Effects of AICAR and exercise on insulin-stimulated glucose uptake, signaling, and GLUT-4 content in rat muscles. Journal of Applied Physiology 94 1373-1379. (doi:10.1152/japplphysiol.00250.2002)

Jeukendrup AE, Saris WH \& Wagenmakers AJ 1998 Fat metabolism during exercise: a review. Part I: fatty acid mobilization and muscle metabolism. International Journal of Sports Medicine 19 231-244. (doi:10.1055/s-2007-971911)

Jorgensen SB, Nielsen JN, Birk JB, Olsen GS, Viollet B, Andreelli F, Schjerling P, Vaulont S, Hardie DG, Hansen BF et al. 2004 The $\alpha 2-5^{\prime}$ AMP-activated protein kinase is a site 2 glycogen synthase kinase in skeletal muscle and is responsive to glucose loading. Diabetes $\mathbf{5 3}$ 3074-3081. (doi:10.2337/diabetes.53.12.3074)

Karatzaferi C, Ferguson RA, van Mechelen W \& Sargeant AJ $2001 a$ Phosphocreatine and ATP content in human single muscle fibres before and after maximum dynamic exercise. Pflügers Archiv: European Journal of Physiology 442 467-474. (doi:10.1007/ s004240100552)

Karatzaferi C, de Haan A, van Mechelen W \& Sargeant AJ $2001 b$ Metabolic changes in single human muscle fibres during brief maximal exercise. Experimental Physiology 86 411-415. (doi:10.1113/eph8602223)

Katz A, Broberg S, Sahlin K \& Wahren J 1986 Leg glucose uptake during maximal dynamic exercise in humans. American Journal of Physiology. Endocrinology and Metabolism 251 E65-E70.

Kaufman MP 2012 The exercise pressor reflex in animals. Experimental Physiology 97 51-58. (doi:10.1113/expphysiol.2011.057539)

Keller C, Steensberg A, Pilegaard H, Osada T, Saltin B, Pedersen BK \& Neufer PD 2001 Transcriptional activation of the IL-6 gene in human contracting skeletal muscle: influence of muscle glycogen content. FASEB Journal 15 2748-2750. (doi:10.1096/fj.01-0507fje)

Kirwan JP, Solomon TP, Wojta DM, Staten MA \& Holloszy JO 2009 Effects of 7 days of exercise training on insulin sensitivity and responsiveness in type 2 diabetes mellitus. American Journal of Physiology. Endocrinology and Metabolism 297 E151-E156. (doi:10.1152/ ajpendo.00210.2009)

Kjaer M \& Galbo H 1988 The effect of physical training on the capacity to secrete epinephrine. Journal of Applied Physiology 64 11-16.

Kjaer M \& Lange K 2000 Adrenergic regulation of energy metabolism. In Sports Endocrinology, pp 181-188. Eds MP Warren \& NW Constantini. New Jersey: Humana Press.

Kjaer M, Secher NH, Bach FW \& Galbo H 1987 Role of motor center activity for hormonal changes and substrate mobilization in humans. American Journal of Physiology. Regulatory, Integrative and Comparative Physiology 253 R687-R695. 
Kjaer M, Engfred K, Fernandes A, Secher NH \& Galbo H 1993 Regulation of hepatic glucose production during exercise in humans: role of sympathoadrenergic activity. American Journal of Physiology. Endocrinology and Metabolism 265 E275-E283.

Kjaer M, Howlett K, Langfort J, Zimmerman-Belsing T, Lorentsen J, Bulow J, Ihlemann J, Feldt-Rasmussen U \& Galbo H 2000 Adrenaline and glycogenolysis in skeletal muscle during exercise: a study in adrenalectomised humans. Journal of Physiology 528 371-378. (doi:10.1111/ j.1469-7793.2000.00371.x)

Kreisman SH, Haltyer JB, Vranic M \& Marliss EB 2003 Combined infusion of epinephrine and norepinephrine during moderate exercise reproduces the glucoregulatory response of intense exercise. Diabetes 52 1347-1354. (doi:10.2337/diabetes.52.6.1347)

Kristiansen OP \& Mandrup-Poulsen T 2005 Interleukin- 6 and diabetes: the good, the bad, or the indifferent? Diabetes 54 S114-S124. (doi:10.2337/ diabetes.54.suppl_2.S114)

Layne JE \& Nelson ME 1999 The effects of progressive resistance training on bone density: a review. Medicine and Science in Sports and Exercise 31 25-30. (doi:10.1097/00005768-199901000-00006)

Lee-Young RS, Griffee SR, Lynes SE, Bracy DP, Ayala JE, McGuinness OP \& Wasserman DH 2009 Skeletal muscle AMP-activated protein kinase is essential for the metabolic response to exercise in vivo. Journal of Biological Chemistry 284 23925-23934. (doi:10.1074/jbc.M109.021048)

Lewis GD, Farrell L, Wood MJ, Martinovic M, Arany Z, Rowe GC, Souza A, Cheng S, McCabe EL, Yang E et al. 2010 Metabolic signatures of exercise in human plasma. Science Translational Medicine 2 33ra37. (doi:10.1126/ scitranslmed.3001006)

Li TL \& Gleeson M 2004 The effect of single and repeated bouts of prolonged cycling on leukocyte redistribution, neutrophil degranulation, IL- 6 and plasma stress hormone responses. International Journal of Sport Nutrition and Exercise Metabolism 14 501-516.

Lihn AS, Pedersen SB, Lund S \& Richelsen B 2008 The anti-diabetic AMPK activator AICAR reduces IL- 6 and IL- 8 in human adipose tissue and skeletal muscle cells. Molecular and Cellular Endocrinology 292 36-41. (doi:10.1016/j.mce.2008.06.004)

Lowenstein JM 1972 Ammonia production in muscle and other tissues: the purine nucleotide cycle. Physiological Reviews 52 382-414.

MacDonald C, Wojtaszewski JF, Pedersen BK, Kiens B \& Richter EA 2003 Interleukin-6 release from human skeletal muscle during exercise: relation to AMPK activity. Journal of Applied Physiology 95 2273-2277. (doi:10.1152/japplphysiol.00242.2003)

Malin SK, Haus JM, Solomon TP, Blaszczak A, Kashyap SR \& Kirwan JP 2013 Insulin sensitivity and metabolic flexibility following exercise training among different obese insulin-resistant phenotypes. American Journal of Physiology. Endocrinology and Metabolism 305 E1292-E1298. (doi:10.1152/ajpendo.00441.2013)

Matsukawa K 2012 Central command: control of cardiac sympathetic and vagal efferent nerve activity and the arterial baroreflex during spontaneous motor behaviour in animals. Experimental Physiology 97 20-28. (doi:10.1113/expphysiol.2011.057661)

Maughan RJ \& Gleeson M 2004 Middle distance events. In The Biochemical Basis of Sports Performance, pp 91-114. Eds RJ Maughan \& M Gleeson. Oxford: Oxford University Press.

McGilvery RW 1975 The use of fuels for muscular work. In Metabolic Adaptation to Prolonged Physical Exercise, pp 12-30. Eds H Howald \& JR Poortmans. Basel: Birkhauser Verlag.

Merrill GF, Kurth EJ, Rasmussen BB \& Winder WW 1998 Influence of malonyl-CoA and palmitate concentration on rate of palmitate oxidation in rat muscle. Journal of Applied Physiology 85 1909-1914.

Meyer RA \& Terjung RJ 1979 Differences in ammonia and adenylate metabolism in contracting fast and slow muscle. American Journal of Physiology. Cell Physiology 6 C111-C118.

Mora-Rodriguez R \& Coyle EF 2000 Effects of plasma epinephrine on fat metabolism during exercise: interactions with exercise intensity. American Journal of Physiology. Endocrinology and Metabolism 278 E669-E676.
Morris JN, Heady JA, Raffle PA, Roberts CG \& Parks JW 1953 Coronary heart disease and physical activity of work. Lancet 1053 111-1120.

Nehlsen-Cannarella SL, Fagoaga OR, Nieman DC, Henson DA, Butterworth DE, Schmitt RL, Bailey EM, Warren BJ, Utter A \& Davis JM 1997 Carbohydrate and the cytokine response to $2.5 \mathrm{~h}$ of running. Journal of Applied Physiology 82 1662-1667.

Nieman DC, Nehlsen-Cannarella SL, Fagoaga OR, Henson DA, Utter A, Davis JM, Williams F \& Butterworth DE 1998 Influence of mode and carbohydrate on the cytokine response to heavy exertion. Medicine and Science in Sports and Exercise 30 671-678. (doi:10.1097/ 00005768-199805000-00005)

Nieman DC, Henson DA, Davis JM, Dumke CI, Utter AC, Murphy EA, Pearce S, Gojanovich G, McAnulty SR \& McAnulty LS 2006 Blood leukocyte mRNA expression for IL-10, IL-1Ra, and IL-8, but not IL-6, increases after exercise. Journal of Interferon \& Cytokine Research 26 668-674. (doi:10.1089/jir.2006.26.668)

Odland LM, Heigenhauser GJ, Lopaschuk GD \& Spriet LL 1996 Human skeletal muscle malonyl-CoA at rest and during prolonged submaximal exercise. American Journal of Physiology. Endocrinology and Metabolism 270 E541-E544.

Olesen J, Gliemann L, Biensø R, Schmidt J, Hellsten Y \& Pilegaard H 2014 Exercise training, but not resveratrol, improves metabolic and inflammatory status in skeletal muscle of aged men. Journal of Physiology 592 1872-1886. (doi:10.1113/jphysiol.2013.270256)

Ostrowski K, Rohde T, Zacho M, Asp S \& Pedersen BK 1998 Evidence that interleukin-6 is produced in human skeletal muscle during prolonged running. Journal of Physiology 508 949-953. (doi:10.1111/j.1469-7793. 1998.949bp.x)

Park SH, Gammon SR, Knippers JD, Paulsen SR, Rubink DS \& Winder WW 2002 Phosphorylation-activity relationships of AMPK and acetyl-CoA carboxylase in muscle. Journal of Applied Physiology 92 2475-2482. (doi:10.1063/1.1497720)

Parkington JD, Siebert AP, LeBrasseur NK \& Fielding RA 2003 Differential activation of mTOR signaling by contractile activity in skeletal muscle. American Journal of Physiology. Regulatory, Integrative and Comparative Physiology 285 R1086-R1090. (doi:10.1152/ajpregu.00324.2003)

Peake JM, Tan SJ, Markworth JF, Broadbent JA, Skinner TL \& Cameron-Smith D 2014 Metabolic and hormonal responses to isoenergetic high-intensity interval exercise and continuous moderate-intensity exercise. American Journal of Physiology. Endocrinology and Metabolism 307 E539-E552. (doi:10.1152/ajpendo. $00276.2014)$

Pedersen BK 2009 The diseasome of physical inactivity-and the role of myokines in muscle-fat cross talk. Journal of Physiology $\mathbf{5 8 7} 5559-5568$. (doi:10.1113/jphysiol.2009.179515)

Pedersen BK 2013 Muscle as a secretory organ. Comprehensive Physiology 3 1337-1362. (doi:10.1002/cphy.c120033)

Pedersen BK \& Febbraio MA 2008 Muscle as an endocrine organ: focus on muscle-derived interleukin-6. Physiological Reviews 88 1379-1406. (doi:10.1152/physrev.90100.2007)

Pedersen BK \& Fischer CP 2007 Physiological roles of muscle-derived interleukin-6 in response to exercise. Current Opinion in Clinical Nutrition and Metabolic Care 10 265-271. (doi:10.1097/MCO. Ob013e3280ebb5b3)

Pedersen BK, Adam Steensberg A \& Schjerling P 2001 Muscle-derived interleukin-6: possible biological effects. Journal of Physiology 536 329-337. (doi:10.1111/j.1469-7793.2001.0329c.xd)

Pedersen BK, Akerstrom TC, Nielsen AR \& Fischer CP 2007 Role of myokines in exercise and metabolism. Journal of Applied Physiology 103 1093-1098. (doi:10.1152/japplphysiol.00080.2007)

Phillips SM, Green HJ, Tarnopolsky MA, Heigenhauser GF, Hill RE \& Grant SM 1996 Effects of training duration on substrate turnover and oxidation during exercise. Journal of Applied Physiology 81 2182-2191.

Pierce GL, Donato AJ, LaRpocca TJ, Eskura I, Silver AE \& Seals DR 2011 Habitually exercising older men do not demonstrate age-associated 
vascular endothelial oxidative stress. Aging Cell 10 1032-1037. (doi:10.1111/j.1474-9726.2011.00748.x)

Ploug T, Galbo H \& Richter EA 1984 Increased muscle glucose uptake during contractions: no need for insulin. American Journal of Physiology. Endocrinology and Metabolism 247 E726-E731.

Ploug T, Galbo H, Ohkuwa T, Tranum-Jensen J \& Vinten J 1992 Kinetics of glucose transport in rat skeletal muscle membrane vesicles: effects of insulin and contractions. American Journal of Physiology. Endocrinology and Metabolism 262 E700-E711.

Pohjanen E, Thysell E, Jonsson P, Eklund C, Silfver A, Carlsson I-B, Krister Lundgren K, Moritz T, Svensson MB \& Antti H 2007 A multivariate screening strategy for investigating metabolic effects of strenuous physical exercise in human serum. Journal of Proteome Research 6 2113-2120. (doi:10.1021/pr070007g)

Randle PJ, Garland PB, Hales CN \& Newsholme EA 1963 The glucose fatty-acid cycle: its role in insulin sensitivity and the metabolic disturbances of diabetes mellitus. Lancet 1 785-789. (doi:10.1016/ S0140-6736(63)91500-9)

Rasmussen BB \& Winder WW 1997 Effect of exercise intensity on skeletal muscle malonyl-CoA and acetyl-CoA carboxylase. Journal of Applied Physiology 83 1104-1109.

Richter EA \& Hargreaves M 2013 Exercise, GLUT4, and skeletal muscle glucose uptake. Physiological Reviews 93 993-1017. (doi:10.1152/ physrev.00038.2012)

Richter EA, Galbo H \& Christensen NJ 1981 Control of exercise-induced muscular glycogenolysis by adrenal medullary hormones in rats. Journal of Applied Physiology 50 21-26.

Richter EA, Nielsen JN, Jørgensen SB, Frøsig C \& Wojtaszewski JF 2003 Signalling to glucose transport in skeletal muscle during exercise. Acta Physiologica Scandinavica 178 329-335. (doi:10.1046/j.1365-201X.2003. 01153.x)

Romijn JA, Coyle EF, Sidossis LS, Gastadelli A, Horowitz JA, Endert E \& Wolfe RR 1993 Regulation of endogenous fat and carbohydrate metabolism in relation to exercise intensity and duration. American Journal of Physiology. Endocrinology and Metabolism 265 E380-E391.

Ropelle ER, Flores MB, Cintra DE, Guilherme Z, Rocha GZ, Pauli JR, Morari J, de Souza CT, Moraes JC, Prada PO et al. 2010 IL-6 and IL-10 anti-inflammatory activity links exercise to hypothalamic insulin and leptin sensitivity through IKK $\beta$ and ER stress inhibition. PLoS Biology $\mathbf{8}$ 1-20. (doi:10.1371/journal.pbio.1000465)

Sarvas JL, Khaper N \& Lees SJ 2013 The IL-6 paradox: context dependent interplay of SOCS3 and AMPK. Journal of Diabetes \& Metabolism $\mathbf{S 1 3}$ 003. (doi:10.4172/2155-6156.S13-003)

Sasaki T, Nakata R, Inoue H, Shimizu M, Inoue J \& Sato R 2014 Role of AMPK and PPAR $\gamma 1$ in exercise-induced lipoprotein lipase in skeletal muscle. American Journal of Physiology. Endocrinology and Metabolism 306 E1085-E1092. (doi:10.1152/ajpendo.00691.2013)

Seals DR, Desouza CA, Donato AJ \& Tanaka H 2008 Habitual exercise and arterial aging. Journal of Applied Physiology 105 1323-1332. (doi:10.1152/japplphysiol.90553.2008)

Secher NH \& Amann M 2012 Human investigations into the exercise pressor reflex. Experimental Physiology 97 59-69. (doi:10.1113/expphysiol.2011.057679)

Spriet LL, Söderlund K, Bergström M \& Hultman E 1987 Anaerobic energy release in skeletal muscle during electrical stimulation in men. Journal of Applied Physiology 62 611-615. (doi:10.1063/1.339788)

Spriet LL, Ren J-M \& Hultman E 1988 Epinephrine infusion enhances muscle glycogenolysis during prolonged electrical stimulation. Journal of Applied Physiology 64 1439-1444.

Starkie RL, Rolland J, Angus DJ, Anderson MJ \& Febbraio MA 2001 Circulating monocytes are not the source of elevations in plasma IL-6 and TNF-alpha levels after prolonged running. American Journal of Physiology. Cell Physiology 280 C769-C774.

Steensberg A, van Hall G, Osada T, Sacchetti M, Saltin B \& Pedersen BK 2000 Production of interleukin- 6 in contracting human skeletal muscles can account for the exercise-induced increase in plasma interleukin-6.

http://joe.endocrinology-journals.org DOI: 10.1530/JOE-14-0408
(C) 2015 Society for Endocrinology Printed in Great Britain
Journal of Physiology 529 237-242. (doi:10.1111/j.1469-7793.2000. 00237.x)

Steensberg A, Febbraio MA, Osada T, Schjerling P, Van Hall G, Saltin B \& Pedersen BK 2001 Interleukin-6 production in contracting human skeletal muscle is influenced by pre-exercise muscle glycogen content. Journal of Physiology 537 633-639. (doi:10.1111/j.1469-7793.2001. 00633.x)

Stephens FB, Constantin-Teodosiu D \& Greenhaff PL 2007 New insights concerning the role of carnitine in the regulation of fuel metabolism in skeletal muscle. Journal of Physiology 581 431-444. (doi:10.1113/ jphysiol.2006.125799)

Stevenson RW, Steiner KE, Davis MA, Hendrick GK, Williams PE, Lacy WW, Brown L, Donahue P, Lacy DB \& Cherrington AD 1987 Similar dose responsiveness of hepatic glycogenolysis and gluconeogenesis to glucagon in vivo. Diabetes 36 382-389. (doi:10.2337/diab.36.3.382)

Timmons JA, Gustafsson T, Sundberg CJ, Jansson E \& Greenhaff PL 1998 Acetyl group availability is a major determinant of the oxygen deficit in human skeletal muscle during submaximal exercise. American Journal of Physiology. Endocrinology and Metabolism 274 E377-E380.

Turner D \& Hoppler H 1999 Muscle energetic: aerobic strategies. In Physiological Determinants of Exercise Tolerance in Humans, pp 29-49. Eds BJ Whipp \& AJ Sargeant. London: Portland Press.

Van Der Vusse GJ \& Reneman RS 1996 Lipid metabolism in muscle. In Handbook of Physiology, American Physiological Society, pp 954-994. Eds LB Rowell \& JT Shepherd. New York: Oxford Press.

Van Loon LJ, Greenhaff PL, Constantin-Teodosiu D, Saris WH \& Wagenmakers AJ 2001 The effect of increasing exercise intensity on muscle fuel utilization in humans. Journal of Physiology 536 295-304. (doi:10.1111/j.1469-7793.2001.00295.x)

Vecht RJ, Graham GW \& Sever PS 1978 Plasma noradrenaline concentrations during isometric exercise. British Heart Journal 40 1216-1220. (doi:10.1136/hrt.40.11.1216)

Victor RG, Seals DR \& Mark AL 1987 Differential control of heart rate and sympathetic nerve activity during dynamic exercise insight from intraneural recordings in humans. Journal of Clinical Investigation 79 508-516. (doi:10.1172/JCI112841)

Victor RG, Secher NH, Lyson T \& Mitchell JH 1995 Central command increases muscle sympathetic nerve activity during intense intermittent isometric exercise in humans. Circulation Research 76 127-131. (doi:10.1161/01.RES.76.1.127)

Wahren J, Hagenfeldt L \& Felig P 1975 Splanchnic and leg exchange of glucose, amino acids, and free fatty acids during exercise in diabetes mellitus. Journal of Clinical Investigation 55 1303-1314. (doi:10.1172/ JCI108050)

Wahren J, Efendi S, Luft R, Hagenfeldt L, Bjorkman O \& Felig P 1977 Influence of somatostatin on splanchnic glucose metabolism in postabsorptive and 60-hour fasted humans. Journal of Clinical Investigation 59 299-307. (doi:10.1172/JCI108641)

Warren MP \& Constantini NW 2000 In Sports Endocrinology. New Jersey, NJ, USA: Humana Press.

Wasserman DH, Spalding JA, Lacy DB, Colburn CA, Goldstein RE \& Cherrington AD 1989 Glucagon is a primary controller of hepatic glycogenolysis and gluconeogenesis during muscular work. American Journal of Physiology. Endocrinology and Metabolism 257 E108-E117.

Wasserman DH \& Cherrington AD 1991 Hepatic fuel metabolism during muscular work: role and regulation. American Journal of Physiology. Endocrinology and Metabolism 260 E811-E824.

Watt MJ, Howlett KF, Febbraio MA, Spriet LL \& Hargreaves M 2001 Adrenaline increases skeletal muscle glycogenolysis, pyruvate dehydrogenase activation and carbohydrate oxidation during moderate exercise in humans. Journal of Physiology 534 269-278. (doi:10.1111/j.1469-7793.2001.t01-1-00269.x)

Weigert C, Düfer M, Simon P, Debre E, Runge H, Brodbeck K, Häring HU \& Schleicher ED 2007 Upregulation of IL-6 mRNA by IL-6 in skeletal muscle cells: role of IL- 6 mRNA stabilization and $\mathrm{Ca}^{2+}$-dependent 
mechanisms. American Journal of Physiology. Cell Physiology 293 C1139-C1147. (doi:10.1152/ajpcell.00142.2007)

Winder WW, Hagberg JM, Hickson RC, Ehsani AA \& McLane JA 1978 Time course of sympathoadrenal adaptation to endurance exercise in man. Journal of Applied Physiology 45 370-374.

Wolsk E, Mygind H, Grøndahl TS, Pedersen BK \& van Hall G 2010 IL-6 selectively stimulates fat metabolism in human skeletal muscle. American Journal of Physiology: Endocrinology and Metabolism 299 E832-E840. (doi:10.1152/ajpendo.00328.2010)

Wu Z, Puigserver P, Andersson U, Zhang C, Adelmant G, Mootha V, Troy A, Cinti S, Lowell B, Scarpulla RC et al. 1999 Mechanisms controlling mitochondrial biogenesis and respiration through the thermogenic coactivator PGC-1. Cell 98 115-124. (doi:10.1016/S00928674(00)80611-X)

Yan B, A J, Wang G, Lu H, Huang X, Liu Y, Zha W, Hao H, Zhang Y, Liu L et al. 2009 Metabolomic investigation into variation of endogenous metabolites in professional athletes subject to strength-endurance training. Journal of Applied Physiology 106 531-538. (doi:10.1152/ japplphysiol.90816.2008)

Yuen DYC, Dwyer RM, Matthews VB, Zhang L, Drew BG, Neill B, Kingwell BA, Clark MG, Rattigan S \& Febbraio MA 2009 Interleukin-6 attenuates insulin-mediated increases in endothelial cell signaling but augments skeletal muscle insulin action via differential effects on tumor necrosis factor- $\alpha$ expression. Diabetes 58 1086-1095. (doi:10.2337/db08-0775)

Received in final form 6 November 2014

Accepted 27 November 2014

Accepted Preprint published online 27 November 2014
Published by Bioscientifica Ltd. 